九州大学学術情報リポジトリ

Kyushu University Institutional Repository

\title{
Screening of Soil for Alcohol-Extracted Organic Compounds by Turbidity Analysis
}

Sakai, Hiroyuki

Railway Technical Research Institute

Okada, Akira

TERM CORPORATION

Fujita, Takeshi

Central Research Laboratory, Hitachi

Wada, Shin-ichiro

Laboratory of Soil Science, Division of Bioproduction Environmental Sciences, Department of Agro-environmental Sciences, Faculty of Agriculture, Kyushu University

https://doi.org/10.5109/19535

出版情報：九州大学大学院農学研究院紀要. 56 (1)，pp.93-97，2011-02. Faculty of Agriculture， Kyushu University

バージョン :

権利関係 : 


\title{
Screening of Soil for Alcohol-Extracted Organic Compounds by Turbidity Analysis
}

\author{
Hiroyuki SAKAI ${ }^{1}$, Akira OKADA ${ }^{2}$, Takeshi FUJITA ${ }^{3}$ \\ and Shin-ichiro WADA*
}

\author{
Laboratory of Soil Science, Division of Bioproduction Environmental Sciences, Department of \\ Agro-environmental Sciences, Faculty of Agriculture, Kyushu University, \\ Fukuoka 812-8581, Japan \\ (Received October 29, 2010 and accepted November 8, 2010)
}

\begin{abstract}
To quickly detect organic compounds in soil, a low-cost screening method has been developed to use a simple procedure without requiring specific reagents or equipment. This method semi-quantitatively detects organic compounds and indicates at concentration levels of 2,000 to $15,000 \mathrm{mg} \mathrm{kg}^{-1}$. The indication will be helpful to know where grounds are polluted with organic compounds at a site, especially when tracking organic compounds in soil during remediation work.
\end{abstract}

\section{INTRODUCTION}

To find areas polluted with organic compounds in the ground or at railroad track sites, an easy and costeffective manner has been developed and being used widely (Lambert et al., 2001). Typical methods are the immunoassay, turbidimetry, colorimetry and total organic carbon (TOC) analysis using oxidation procedure. With the popular turbidimetry based methods, the organic compounds in soil samples collected are quickly extracted into alcohol in order to detect organic compounds by observing turbidity caused through the salting-out procedure. It takes five minutes to extract organic compounds and one minute more to salt them out. The turbidity can be detected with a small scale hand carry-able UV/VIS photometer. In the case of petroleum, its detection limit is $1,000 \mathrm{mg} \mathrm{kg}^{-1}$ for a $2 \mathrm{~g}$ soil sample.

Basically, there is no regulation to control allowable concentration limits of organic compounds, especially petroleum, in the environment. Petroleum or an organic compound is commonly used in railroad industries as a fuel or a lubricant. It is not necessarily harmful to human beings. Petroleum spilled on the ground is not welcome, however, for neighbors around railroad tracks, since it would be conveyed by groundwater streaming to wells for drinking water after it has soaked deep in the ground. Petroleum sometimes smells bad and occasionally has possibility to catch on fire even while it is still in the ground. Besides the reasons mentioned above, which are not essential or critical, the intention to remove petroleum from soil is to eliminate its ugly appearance. This kind of pollution is called visual contamination.

The pollution by organic compounds in railroad premises occurs during train operation and maintenance work. Some trains leak petroleum from their fuel tanks

\footnotetext{
Railway Technical Research Institute, Japan Railways, Hikaricho 2-8-38, Kokubunji 185-8540, Japan

2 TERM COOPORATION, 1-1-32 Shin-Urashima-cho Kanagawaku, Yokohama 221-0031, Japan

3 Central Research Laboratory, Hitachi, Higashi-Koigakubo 1-280, Kokubunji, Tokyo 185-8601, Japan

* Corresponding author (wadasi@agr.kyushu-u.ac.jp)
}

on the way while running. Leakage contaminates the ground, which are from fuel tanks at gas stations in rolling stock bases. Besides the contamination taking place underground, it is not occasional but relatively often that fuel drips, while rolling stock is refueled, scattering the drops on the surface ground. These incidents have taken place for a long time, though the volume of contaminant at each incident is rather small. Thus, petroleum leakage will gradually be accumulated at particular spots in railroad premises day by day.

To remove petroleum from the ground, it is supposed that the petroleum be extracted from the site or the ground be remediated by decomposing petroleum using oxidizing agents. However, a problem in taking care of the petroleum as a pollutant in the ground is to know prior to the treatment how large and deep it is in the ground. In the case of railroad premises, inspections are implemented under specific conditions or at narrow but so long tracks where a lot of trains run at short intervals. There are a number of precise analytical methods to quantitatively determine petroleum in soil, namely, GC-MS and HPLC-MS (Shibata, 1997; Fujita, 1986; Alaska Department of Environmental Conservation, 1999). Unfortunately, however, these methods can be applied only in laboratories limited by the equipment scale. Thus, a simple and quick way has been desired to detect, but not to determine, petroleum at a site. Testkits for petroleum are commercially available, which apply turbidity analysis for its detection (American Society of Testing Materials, 1998). A test-kit consists of a simple balance and a small-scale photometer and uses an alcohol as a solvent and a reagent for salting-out in vials. The photometer is not costly as it features a simple structure with one or two wavelengths. However, supplements of the solvent and reagents are not inexpensive. Normally, it costs at least 30 US dollars per sample. This test-kit detection manner is convenient but does not induce users to casually try it.

To overcome these difficulties in quickly inspecting railroad tracks and promote turbidity analysis for petroleum at a low expense, an easy way has been developed. The method is to screen soil on site for petroleum on 
railroad tracks using common reagents and equipments, which are usually available wherever analytical work has been done or in every laboratory. This report describes the screening method based on a turbidity analytical technique to quickly and semi-quantitatively detect organic compounds through a simple procedure using ordinary chemicals and common equipment at a site in a short time.

\section{PRINCIPLE}

Even the petroleum with a large number of carbon atoms in the formula can be mixed with lower alcohol. This is because alcohol has affinity with petroleum as it has alkyl groups while having hydrophobic ones. Lower alcohol cannot dissolve petroleum but solvate it. However, alcohol is still polar. When the ion strength of an alcohol solution solvating petroleum is immediately increased, petroleum is quickly isolated. This is a salting-out process resulting in turbidity, white in color, in the solution. Fig. 1 shows the turbidity appeared in a solution containing $82 \mathrm{mg} \mathrm{L}^{-1}$ of light oil through the process. The degree of turbidity would depend on the concentration of oil pools originating from petroleum released from alcohol. The turbidity can simply be observed with a UV/VIS photometer.

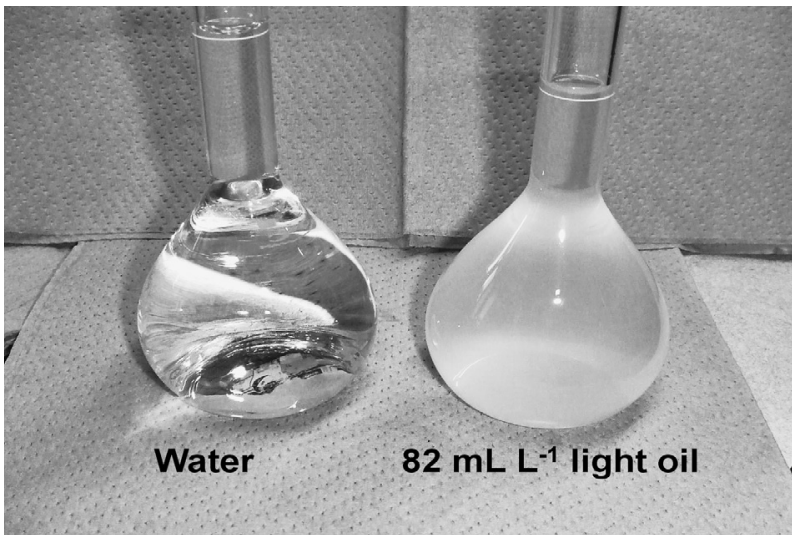

Fig. 1. Turbidity appeared in a 2 -propernol solution at an light oil concentration of $82 \mathrm{mg} \mathrm{L}^{-1}$.

\section{MATERIALS AND METHODS}

A soil sample was mixed with 2-propanol as an alcohol. The soil-to-liquid ratio in volume would depend on the estimated amount of petroleum. The mixture was shaken for five minutes and then filtrated with a $0.45 \mu \mathrm{m}$ membrane filter. The filtrate was diluted with water up to a convenient volume. A 30\% sodium chloride solution, $1 \mathrm{~mL}$ in volume, was added into the diluted filtrate. The filtrate was shaken for one minute and stood for a while. The absorbance of the solution was measured at the wavelength of $660 \mathrm{~nm}$ using a quartz cell with a 10-mm optical path. Fig. 2 schematically illustrates the entire procedure.

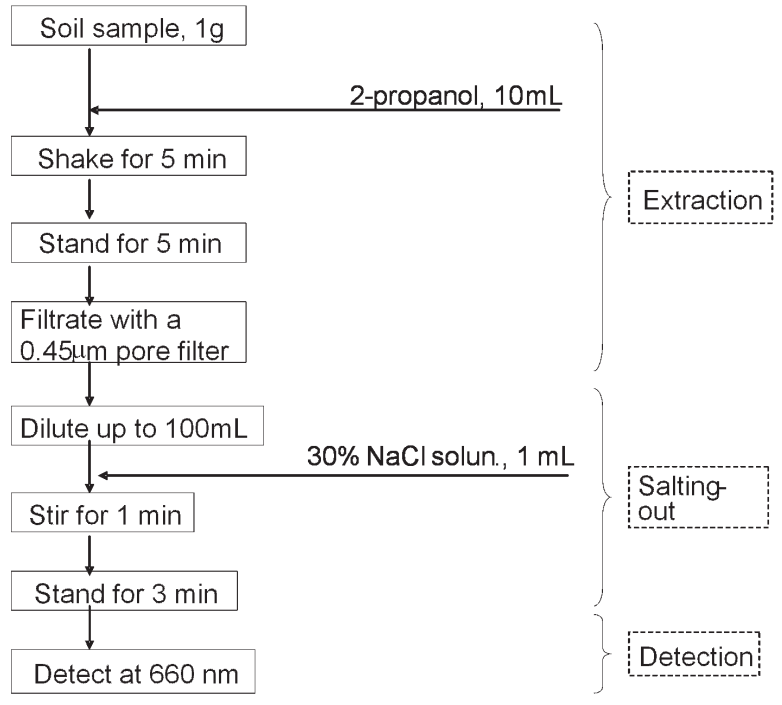

Fig. 2. Procedure for turbidity analysis of petroleum using 2-propanol as a solvent.

\section{RESULTS AND DISCUSSION}

To determine the procedure to extract organic compounds from soil into alcohol and salt-out the compound extracted, 2-propernol was used as an alcohol and sodium chloride as a salting-out reagent, respectively. Light oil was used as an organic compound to optimize the conditions. A small amount or $1 \mathrm{~g}$ of soil was weighed out to ensure easy operation during the extraction.

As Fig. 2 shows, the screening method consists of three steps i.e., (1) extraction of organic compounds into alcohol, (2) salting-out of the compounds to cause turbidity and (3) detection of the turbidity generated depending upon the concentration of the compounds. The ratio of soil to alcohol is a sort of important factor to facilitate the extraction operation with solid samples but still to achieve successful detection. If the ratio is low, the solution becomes sticky. If it is high on the other hand, the extraction leaves large volumes of the solution with low concentrations of the compounds requiring a complicated operation and resulting in difficulties to detect. Thus, the ratio of 1:10 was chosen for a procedure to simply extract organic compounds from soil and ensure easy detection. This ratio normally gives $10 \mathrm{~mL}$ or less of the 2-propanol solution after light oil is extracted as the amount of soil collected is $1 \mathrm{~g}$.

In the step for salting-out of light oil, the 2-propanol solution shall first be diluted with water, which is provided through the extraction. All the parameters for the salting-out procedure were determined with the diluted 2-propanol solution containing light oil as an analyte to obtain the maximum turbidity intensity. To successfully form the turbidity of light oil when saltedout with sodium chloride, the 2-propanol concentration was optimized. Fig. 3 shows the variation of the turbidity indicated as absorbance when the concentration of 2 -propanol was increased. In the range of 2-propanol concentration over 10\%, the turbidity slowly increased. 
To simplify the procedure, a value of $10 \%$ was adopted as the 2-propanol concentration after dilution. The volume of the solution would be $10 \mathrm{~mL}$ or below. The 10-times dilution of the 2-propanol solution will give a $100 \mathrm{~mL}$ solution. To avoid complicated calculation at a site, the extracted solution was simply diluted up to $100 \mathrm{~mL}$ with water.

The salting-out reagent or sodium chloride is to be dissolved into the diluted 2-propanol solution, the amount of which is large enough to salt-out light oil from the solution. Fig. 4 suggests that over $1 \mathrm{~mL}$ of $30 \%$ sodium chloride solution works to cause turbidity, which is added to the diluted 2-propanol solution containing light oil.

After adding sodium chloride for the salting-out operation, the flask containing the solution was shaken to complete the turbidity generation in the solution. Fig. 5 shows that the turbidity intensity expressed in absorbance slowly increased with the shaking time. However, the change is not drastic. Thus, the shaking time of $1 \mathrm{~min}$ was adopted.

Fig. 6 illustrates the spectrum of the turbidity caused in the solution prepared through the salting-out process. There is no significant difference in the turbidity intensity indicated as absorbance against wavelength. The wavelength of $660 \mathrm{~nm}$ is used even in this case as the wavelength is common for turbidity analysis.

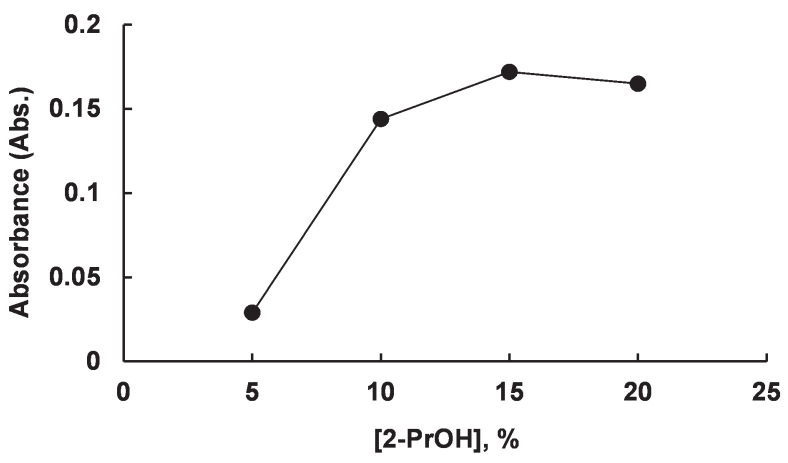

Fig. 3. Changes in the turbidity intensity of light oil against the 2-propanol concentration. Light oil, $60 \mathrm{mg} \mathrm{L}^{-1} ; 30 \%$ sodium chloride solution, $1 \mathrm{~mL}$

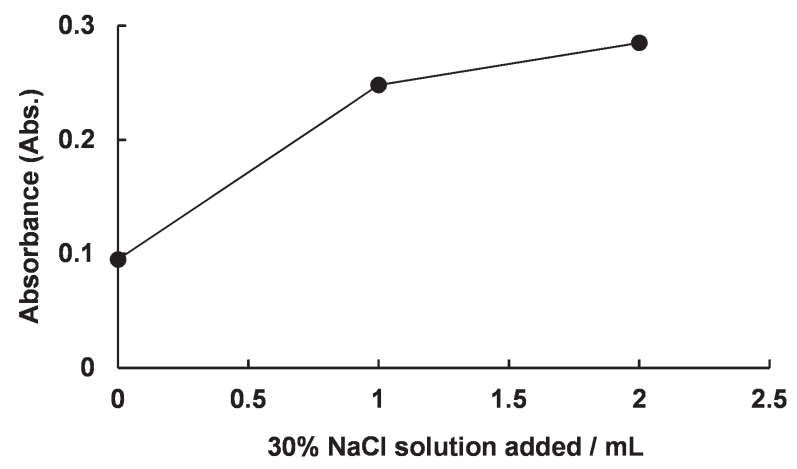

Fig. 4. Salting-out caused by adding sodium chloride into 2-propanol solvating light oil. Light oil, $100 \mathrm{~g} \mathrm{~L}^{-1}$; 2-preopanol, $10 \%$.

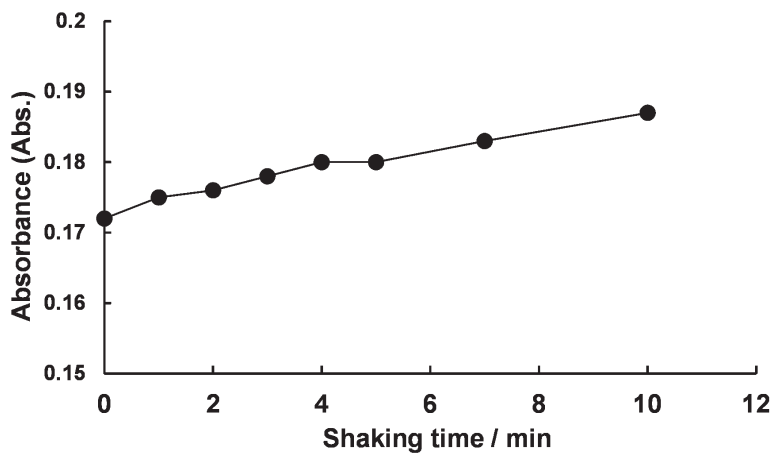

Fig. 5. Relationship between shaking time and turbidity indicated as absorbance. Light oil, $50 \mathrm{mg} \mathrm{L}^{-1}$; 2-propanol, 10\%; $30 \%$ sodium chloride solution, $1 \mathrm{~mL}$.

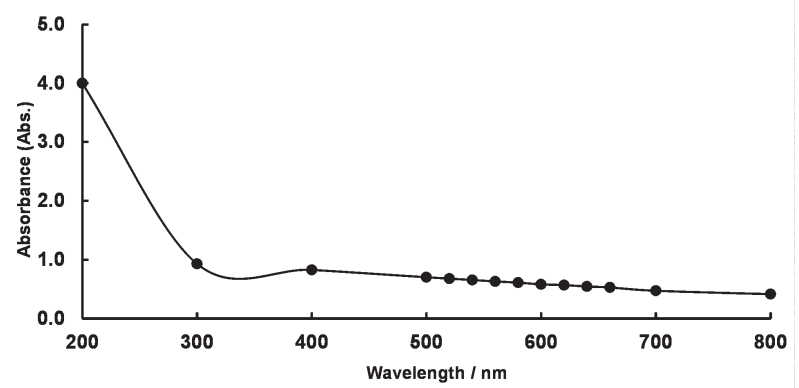

Fig. 6. The spectrum of the turbidity taking place in the mixture of 2-propanol and light oil salted-out. Light oil, $132 \mathrm{mg} \mathrm{L}^{-1} ; 30 \%$ sodium chloride solution, $1 \mathrm{~mL} ; 2$-propanol, $15 \%$.
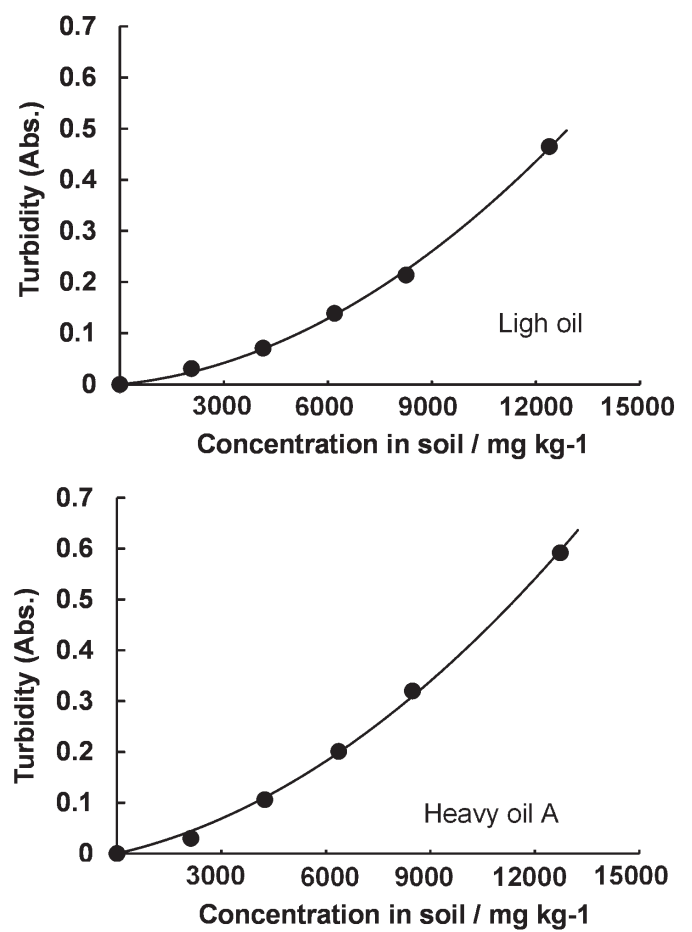

Fig. 7. Working curves for light and heavy oils. 


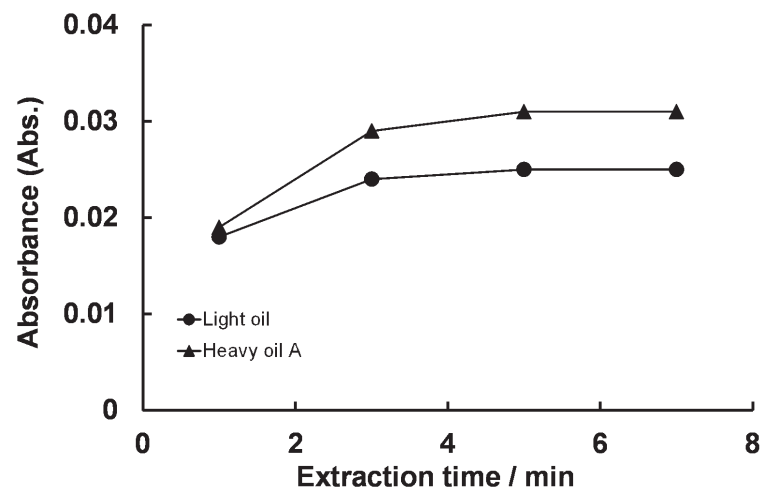

Fig. 8. Extraction of light and heavy oils from soil with 2-propanol. Concentration, $2500 \mathrm{mg} \mathrm{kg}^{-1}$ in soil.

Under the optimized detecting conditions, the working curves were eventually obtained for light oil. Fig. 7 indicates the dynamic range. The curve is smooth enough to calculate the concentration of light oil in soil samples by observing the absorbance of the prepared sample solution, which means the turbidity intensity, though the linearity of the working curve is poor. The Fig. also illustrates the working curve for heavy oil A, which was available under the same conditions optimized for light oil.

Screening does not aim at obtaining exact concentration values but desires to detect target compounds without fail. Thus, the reproducibility of the detection by the screening methods shall be quite high. The reproducibility of turbidity intensities measured were $8.3 \%$ and 5.0\% ( $\mathrm{n}=9)$, respectively, when $50 \mathrm{mg} \mathrm{L}^{-1}$ light oil and heavy oil A were detected with the working curves.

The conditions were already optimized for generating turbidity by light oil. Before the process for turbidity generation, the oil should successfully be extracted from soil into 2-propanol. Fig. 8 indicates the turbidity intensities of light oil and heavy oil A at different extraction times. As the Fig. illustrates, $5 \mathrm{~min}$ is long enough for the extraction.

Water contents in soil samples disturb the extraction
Table 1. Influence of water on turbidity

\begin{tabular}{lccc}
\hline \multirow{2}{*}{ Concentration spiked } & \multicolumn{3}{c}{ Observed concentration value / $\mathrm{mg} \mathrm{kg}^{-1}$} \\
\cline { 2 - 4 } & WC, 6.5\% & WC 14.4\% & WC 32.2\% \\
\hline Light oil, 2500 $\mathrm{mg} \mathrm{kg}^{-1}$ & 1500 & 1000 & 800 \\
Heavy oil A, 2500 $\mathrm{mg} \mathrm{kg}^{-1}$ & 1500 & 1300 & 900 \\
\hline
\end{tabular}

WC, water content; sample, $1 \mathrm{~g}$.

of oil in this turbidity analysis. Table 1 points-out the influence on the extraction by water contained in soil samples. The water content over 30\% reduced the concentration values to one-third the concentration spiked into the soil sample in advance. This means that high water contents bring poor recoveries of organic compounds. Even in this case, however, the compound is still detected. As discussed earlier, the goal of screening methods is to detect target compounds at least at concentrations allowable in the environment. Thus, this screening method or turbidity analysis for organic compounds does not bother with the low recovery during the process of the extraction with 2-propanol, if the deviation in the recovery remains constant.

The detection performance by this method was confirmed by using artificial soil samples spiked with $500 \mathrm{mg}$ $\mathrm{kg}^{-1}$ or 2,00 $\mathrm{mg} \mathrm{kg}^{-1}$ petroleum. Light oil and heavy oil A were used as petroleum. See Table 1 for the result. To compare with other analytical methods, it also indicates the results obtained through carbon tetrachloride extraction/infrared spectrophotometry (IR) and gravimetry of extracts with n-hexane.

All the results listed in Table 2 suggest that concentration values obtained from respective methods are less than those spiked into soil. Gravimetry of extracts with n-hexane gave the poorest results. The concentration values indicated by carbon tetrachloride extraction/IR are around the concentration spiked. Carbon tetrachloride used this way will be prohibited, however, from using in 10 years by the Montreal Agreement for substitutes for chlorofluorocarbon. Thus, carbon tetrachloride

Table 2. Detection of petroleum in soil samples spiked with light oil or heavy oil A

\begin{tabular}{|c|c|c|c|c|}
\hline \multicolumn{2}{|l|}{ Sample } & \multicolumn{3}{|c|}{ Concentration detected/ mg kg ${ }^{-1}$} \\
\hline Petroleum spiked & Texture & $\begin{array}{l}\text { Alcohol extraction/ } \\
\text { turbidity analysis } \\
\text { (Sample: } 2 \mathrm{~g} \text { for } \\
500 \mathrm{mg} \mathrm{kg}^{-1}, 1 \mathrm{~g} \text { for } \\
2500 \mathrm{mg} \mathrm{kg}^{-1} \text { ) }\end{array}$ & $\begin{array}{c}\text { Carbon } \\
\text { tetrachloride } \\
\text { extraction/IR } \\
\text { (Sample, } 5 \mathrm{~g} \text { ) }\end{array}$ & $\begin{array}{c}\text { Gravimetry of } \\
\text { extracts with } \\
\text { n-hexane } \\
\text { (Sample, } 10 \mathrm{~g} \text { ) }\end{array}$ \\
\hline $500 \mathrm{mg} \mathrm{kg}^{-1}$ light oil & Medium & 200 & 600 & 200 \\
\hline $2500 \mathrm{mg} \mathrm{kg}^{-1}$ light oil & Medium & 1300 & 1700 & 900 \\
\hline $500 \mathrm{mg} \mathrm{kg}^{-1}$ light oil & Fine & 200 & 600 & 300 \\
\hline $2500 \mathrm{mg} \mathrm{kg}^{-1}$ light oil & Fine & 1100 & 2000 & 800 \\
\hline $500 \mathrm{mg} \mathrm{kg}^{-1}$ heavy oil A & Medium & 500 & 400 & 300 \\
\hline $2500 \mathrm{mg} \mathrm{kg}^{-1}$ heavy oil A & Medium & 2100 & 2000 & 900 \\
\hline $500 \mathrm{mg} \mathrm{kg}^{-1}$ heavy oil A & Fine & 400 & 400 & 200 \\
\hline $2500 \mathrm{mg} \mathrm{kg}^{-1}$ heavy oil A & Fine & 2100 & 1800 & 800 \\
\hline
\end{tabular}


extraction/IR cannot be applied any more in the immediate future even while it gives good results for petroleum analysis. Good reproducibility of $8.3 \%$ and $5.0 \%$ was obtained with $50 \mathrm{mg} \mathrm{kg}^{-1}$ light oil and heavy oli A, respectively in the alcohol extraction-turbidimetry analysis. A low cost of chemicals, less than one US \$ per test, is rquuired for this turbidity analysis since 2-propanol and sodium chloride are very common. This method can still work as a screening method or detection of petroleum with a simple and quick and cost effective procedure.

Unfortunately, this method has no selectivity for analytes or organic compounds. Thus, it is impossible to determine organic compounds including petroleum, aromatic compound and vegetable oil or others to show their respective concentration values. However, the purpose to find or track petroleum in the ground is not to qualify organic compounds or obtain exact concentration values. The goal of this method is to screen soil or detect petroleum at least above a few thousand $\mathrm{mg} \mathrm{kg}^{-1}$ levels directly at a site. Originally, the method has less curiosity to determine organic compounds including petroleum but intends detecting those as the total amount without selectivity. Thus, the detection is ready to be disturbed by interferences, surfactants or other oil-like materials.

To be stressed, this method can be used as a screening method for petroleum in soil in a simple manner at a site, or inspection of railroad tracks, for example. It also enables users to try to do screening without being concerned on the cost for the inspection. This is another goal of this method. This is because analytical chemistry should be in practical use with good cost performance.

\section{REFERENCES}

Alaska Department of Environmental Conservation 1999 General guidance for selecting petroleum hydrocarbon field screening methods. ASPS \#97-0113; Contract \#18-1021-97

American Society for Testing Materials 1999 Turbidimetric screening method for total recoverable petroleum hydrocarbons in soil, ASTM Method 9074

Fujita, M. 1986 Analytical methods for oil. Kankyo-toSokuteigijutsu, 14: 35-47

Lambert, P., M. Fingas and M. Goldthrop 2001 An evaluation of filed total petroleum hydrocarbon (TPH) systems. J. Hazard. Mater. 83: 65-81

Shibata, Y. 1997 Determination of oil constituents. KankyoKagaku, 7: 577-593 